\title{
The influence of male parr body size and mate competition on fertilization success and effective population size in Atlantic salmon
}

\author{
MATTHEW W. JONES* \& JEFFREY A. HUTCHINGS \\ Department of Biology, Dalhousie University, Halifax, Nova Scotia B3H 4 J1, Canada
}

\begin{abstract}
Alternative mating strategies in male Atlantic salmon, Salmo salar, are characterized by variability in body size and mate competition. Controlling breeding numbers of larger, older anadromous males, we examined whether body size of mature male parr influenced fertilization success and whether such an association was affected by mate competition among parr. Variation at three to four hypervariable microsatellite loci was used to determine individual paternity of 53-60 offspring from two or three nests from each experimental treatment. Although individual and total parr reproductive success differed significantly among nests within treatments, there was no relationship between parr size and individual reproductive success at any level of competition when anadromous males were involved. However, in a single treatment having no anadromous male, the influence of body size on parr fertilization success was highly significant. Combining data from all treatments, parr body size was an important predictor of the probability of an individual being involved in spawning. We found a negative relationship between total parr reproductive success and intensity of anadromous male competition. To our knowledge, the present study is the first to estimate the effective number of males from individual fertilization success in fish. Our estimates of $N_{\mathrm{e}}$ should not be taken as absolute and may have a downward bias because we did not sample all nests and we used a proxy for lifetime reproductive success. They do, however, illustrate how mature male parr can greatly increase the effective number of males when the latter is estimated from anadromous individuals alone. Although reproductive success by mature male parr increases the effective number of males, this increase seems likely to be most pronounced in natural populations when the number of anadromous males is low.
\end{abstract}

Keywords: alternative mating strategies, effective population size, reproductive success, Salmo salar.

\section{Introduction}

Atlantic salmon, Salmo salar, have variable life histories. A salmon's life cycle can consist of a freshwater, parr component and a period at sea followed by a return to that salmon's natal river to spawn. Alternatively, some males forego the marine component prior to maturation. Those males that mature in fresh water later can smoltify and become anadromous while others remain in fresh water and later re-mature (Hansen et al., 1989). Parr that previously matured are believed to experience higher mortality than non-maturing parr in fresh water (Hutchings \& Myers, 1994) and later at sea (Berglund et al., 1992). Notwithstanding a strong environmental influence (e.g. Prévost et al., 1993), there is evidence of a

*Correspondence. E-mail: mwjones@is2.dal.ca heritable component to male parr maturation (e.g. Herbinger \& Newkirk, 1990 and references therein). This variation in salmonid male maturation may have evolved as a mixed evolutionarily stable strategy maintained by negative frequency-dependent selection (Gross, 1985; Hutchings \& Myers, 1994).

Mature male parr must compete with larger anadromous males for access to anadromous females for fertilization opportunities. Studies examining the reproductive success of mature male parr have demonstrated that mature male parr, as a group, are successful in fertilizing some eggs (Hutchings \& Myers, 1988; Jordan \& Youngson, 1992; Morán et al., 1996; Thomaz et al., 1997). But, given that selection acts at the level of the individual, factors associated with individual reproductive success are also of interest. During spawning, mature male parr are arranged in a hierarchical manner 
with the largest male nearest the female (Myers \& Hutchings, 1987). A recent study on mature male parr reproductive success documented a positive relationship between individual parr size and reproductive success when six parr were competing with one anadromous male for fertilization opportunities with one anadromous female (Thomaz et al., 1997). The cost of maintaining this improved access to the female may increase with larger numbers of competitors to a point at which body size has no influence on fertilization success (Hutchings \& Myers, 1994).

Reproductive success by mature male parr can have implications for a population's effective size (L'AbéeLund, 1989; Morán \& García-Vázquez, 1998), subsequently altering the effective rate of gene flow among populations (Morán et al., 1996). The effective number of males in a population can be estimated if individual male reproductive success is known (e.g. Lande \& Barrowclough, 1987). Previous studies on Atlantic salmon reproductive success were unable to quantify individual reproductive success either due to the limitation of the genetic markers at the time (e.g. Hutchings \& Myers, 1988), or, due to unsuitable sample sizes, were unable to attempt to quantify the influence parr success has on the effective population size (e.g. Thomaz et al., 1997; Martinez et al., 2000). In contrast, the extensive variation found within and among loci, the minimal tissue requirements, and the relative ease of the analysis render microsatellite loci highly amenable to parentage experiments (O'Reilly \& Wright, 1995; O'Connell \& Wright, 1997). This technique permits larger numbers of individuals to be used in experiments, increases the scope of replication, and enables one to quantify individual reproductive success at sample sizes suitable for determining the influence of mature parr reproductive success on the effective number of males.

The objectives of this study were thus two-fold. Firstly, we tested the effects of parr body size and intensity of mate competition on individual reproductive success, and secondly, we quantified the effect mature male parr can have on the effective number of males. Both of these objectives were addressed by using highly variable microsatellite loci to assign paternity.

\section{Materials and methods}

\section{Field experiment}

Experiments were undertaken in outdoor flow-through raceways at the Margaree Fish Hatchery, Nova Scotia, Canada $\left(46^{\circ} 21^{\prime} \mathrm{N}, 60^{\circ} 58^{\prime} \mathrm{W}\right)$, from October 31 to December 9 1996. The raceways $(14.6 \mathrm{~m} \times 1.2 \mathrm{~m})$ were divided equally into four sections using a barrier of $0.9 \mathrm{~mm}$ square vexar mesh in a wooden frame. Substrate suitable for spawning was added to a depth of $30 \mathrm{~cm}$. Running ripe mature male parr were electrofished from nearby tributaries of the Margaree River and held in the hatchery facility for one week prior to the experiments. Anadromous males were obtained from the fish trap on Lake O'Law River, the largest of Margaree River's tributaries. Females were obtained by seining the Margaree River.

We established 13 single anadromous pair experimental treatments with varying numbers of parr (three replicates of three parr and two replicates of five, seven, 10 , and 20 parr) of different sizes (range $81-123 \mathrm{~mm}$ ). We created this number of treatments to have replication over the wide range of number of parr that typically attend spawning events in the wild as well as in anticipation of not having all treatments being successful. The parr were divided into three size classes: 81$90 \mathrm{~mm}(84.9 \pm 2.7 \mathrm{~mm}), 91-110 \mathrm{~mm}(97.9 \pm 5.7 \mathrm{~mm})$, and $111-123 \mathrm{~mm}(116.9 \pm 3.7 \mathrm{~mm})$. Parr were placed in each section prior to the addition of the anadromous salmon. Each treatment was randomly assigned to a section in the raceways (see Fig. 1 for treatment placement, details on anadromous salmon lengths, and number of parr from each size class in each treatment). After all spawning was complete in December 1996, each fish was measured, weighed and sampled (fin tissue) for DNA analysis. Eyed embryos were collected from two or three randomly chosen nests from each treatment in March 1997. Parr and embryo collection was facilitated by the ability to lower the water levels in the raceways.

Unintentional fish movement occurred when the anadromous fish were placed in their sections prior to the covering of the enclosures with netting. Additionally, in one case, an anadromous female broke through the vexar partition, making future parr movement between sections possible. To prevent further disturbance to the fish, the netting was not nailed down as originally planned.

\section{Genetic analysis}

DNA was extracted from all potential parents and from 60 offspring from each of two or three nests per treatment. Each dissected embryo head or small subsample of fin tissue (approximately $50 \mathrm{mg}$ ) was digested in $100 \mu \mathrm{L}$ of eyeball buffer $(10 \mathrm{~mm}$ Tris, $50 \mathrm{~mm} \mathrm{KCl}$, $0.5 \%$ Tween 20$)$ and proteinase $\mathrm{K}(0.1-0.4 \mu \mathrm{g})$ in a $500 \mu \mathrm{L}$ tube and incubated for 4 hours to overnight at $45-55^{\circ} \mathrm{C}$. Samples were vortexed $2-3$ times during this digestion. Samples were heated at $94^{\circ} \mathrm{C}$ for $5-10 \mathrm{~min}$ to kill the proteinase $\mathrm{K}$, frozen at $-80^{\circ} \mathrm{C}$ (for times varying 


\begin{tabular}{|c|c|c|c|}
\hline $\begin{array}{c}(4) \\
o^{7}: 576 \mathrm{~mm} \\
\text { + }: 796 \mathrm{~mm} \\
20 \mathrm{parr} \\
12: 6: 2\end{array}$ & $\begin{array}{c}(8) \\
\sigma^{r}: 560 \mathrm{~mm} \\
\circ: 772 \mathrm{~mm} \\
15 \text { parr } \\
9: 4: 1\end{array}$ & $\begin{array}{c}(12) \\
\sigma^{7}: 578 \mathrm{~mm} \\
\text { o }: 790 \mathrm{~mm} \\
3 \text { parr } \\
1: 2: 0\end{array}$ & \\
\hline $\begin{array}{c}(3) \\
o^{x}: 585 \mathrm{~mm} \\
\text { o: } 717 \mathrm{~mm} \\
7 \text { parr } \\
4: 2: 1\end{array}$ & $\begin{array}{c}(7) \\
\sigma^{7}: 580 \mathrm{~mm} \\
\text { ᄋ: } 840 \mathrm{~mm} \\
3 \text { parr } \\
1: 2: 0\end{array}$ & $\begin{array}{c}(11) \\
\sigma^{\pi}: 640 \mathrm{~mm} \\
\text { o: } 756 \mathrm{~mm} \\
7 \text { parr } \\
4: 2: 1\end{array}$ & \\
\hline $\begin{array}{c}(2) \\
\sigma^{\top}: 584 \mathrm{~mm} \\
+: 720 \mathrm{~mm} \\
15 \text { parr } \\
9: 4: 1\end{array}$ & $\begin{array}{c}(6) \\
\sigma^{r}: 523 \mathrm{~mm} \\
\text { o: } 753 \mathrm{~mm} \\
5 \text { parr } \\
3: 1: 1\end{array}$ & $\begin{array}{c}(10) \\
\sigma^{\pi}: 582 \mathrm{~mm} \\
\text { o }: 770 \mathrm{~mm} \\
10 \text { parr } \\
6: 3: 1\end{array}$ & \\
\hline $\begin{array}{c}(1) \\
o^{x}: 580 \mathrm{~mm} \\
+: 765 \mathrm{~mm} \\
3 \text { parr } \\
1: 2: 0\end{array}$ & $\begin{array}{c}(5) \\
\sigma^{7}: 573 \mathrm{~mm} \\
\text { o }: 724 \mathrm{~mm} \\
10 \text { parr } \\
6: 3: 1\end{array}$ & $\begin{array}{c}(9) \\
\sigma^{7}: 580 \mathrm{~mm} \\
+: 830 \mathrm{~mm} \\
5 \text { parr } \\
3: 1: 1\end{array}$ & $\begin{array}{c}(13) \\
o^{*}: 590 \mathrm{~mm} \\
\text { o: } 762 \mathrm{~mm} \\
20 \text { parr } \\
12: 6: 2\end{array}$ \\
\hline
\end{tabular}

Fig. 1 Single pair treatment experimental design in Atlantic salmon with the anadromous male ( $\hat{o})$ and female $(+)$ lengths and the number of mature male parr (parr) in each section. Ratio represents the number of parr from each size class (81-90 mm; 91-110 mm; 111-123 mm). Numbers in parentheses indicate section number, and arrows indicate location of water inflow.

from overnight to several months), thawed, centrifuged at $16000 \mathrm{~g}$ (Eppendorf microcentrifuge) for $5 \mathrm{~min}$, and then diluted $100 \times$. Two $\mu \mathrm{L}$ of this DNA (approximate concentration 3-300 ng) was used for microsatellite analysis which was carried out using the hyper-variable loci developed and described by O'Reilly et al. (1996). Specifically, the tetranucleotide loci Ssa171, Ssa197, and Ssa202 were examined on all samples. In addition, the dinucleotide locus Ssa85 was examined in larger treatments or to distinguish between two and three potential fathers. In the few cases where these loci proved insufficient (14 of 1309 embryos genotyped, four from section 10 , one from section 13, and nine from section 7; see Fig. 1 and Table 1 for section designations), additional loci were employed until paternity could be unambiguously established. In descending order, these dinucleotide loci were $S s a 12$ (O'Reilly, 1997), Omy105, and Omy38 (Heath et al., in press). To prevent any bias in the samples, microsatellite analysis was repeated on all individuals that had partial genotype information but for which parentage could not be assigned. No further attempts were made to genotype those embryos that had not amplified at any locus if the number of embryos from a nest that could be assigned parentage was greater than 50 .

\section{Data analyses}

Gene diversity at each locus in salmon from the Margaree River (sample sizes were 157, 166, 168, and 131 salmon for Ssa202, Ssa197, Ssa171, and Ssa85, respectively) was calculated as the heterozygosity expected under Hardy-Weinberg equilibrium, using TFPGA (Miller, 1997). Paternity was determined by first identifying the maternal allele at each locus (when possible) and then using the composite multilocus genotype to identify the father. In more complex treatments (e.g. when two females were present or when several males shared alleles at several loci), the program PROBMAX (Danzmann, 1997) was used to determine parentage. This also allowed manipulation of the data set to identify potential misgenotyping (see PROBMAX program manual).

In one treatment (section 11), 25 embryos could not be assigned fathers. After subtracting the maternal alleles, there were four putative paternal alleles at $\$ s a 202$ and three at each of Ssa171 and Ssa197. Alleles at Ssa171 and Ssa197 were clustered with each unique allele from Ssa202 in which they co-occurred in the same embryo. Two clear groups emerged, each representing a presumably unsampled father. With two new putative paternal multilocus genotypes determined, the parentage analysis was rerun and paternity successfully assigned. In another treatment (section 13), all offspring were triploid, containing the maternal genotype and an additional allele at some or all loci. At those loci having only the maternal genotype, the paternal allele was assumed to be either one of the maternal alleles and paternity was determined treating either allele as possible.

\section{Estimating $\mathrm{N}_{\mathrm{e}}$ males}

Following Lande \& Barrowclough (1987), the effective number of males in each treatment was calculated as:

$\left.N_{e m}=\left(\begin{array}{ll}N_{m} \bar{\kappa}_{m} & 1\end{array}\right) /\left[\kappa_{m}+\sigma_{k m}^{2} / \bar{\kappa}_{m}\right) \quad 1\right]$

where $N_{m}$ is the actual number of males, $\kappa_{m}$ and $\sigma_{\mathrm{km}}^{2}$ represent the number of offspring and associated 


\begin{tabular}{lccrl}
\hline Section & $\begin{array}{c}\text { No. of } \\
\text { males }\end{array}$ & $\begin{array}{c}\text { No. of } \\
\text { females }\end{array}$ & $\begin{array}{c}\text { No. of } \\
\text { parr }\end{array}$ & \multicolumn{1}{c}{ Comments } \\
\hline 1 & 1 & 0 & 3 & Female left prior to spawning \\
2 & 1 & 0 & 12 & Female left prior to spawning \\
3 & 1 & 2 & 7 & Female arrived prior to spawning \\
4 & 1 & 2 & 20 & No spawning - upstream section \\
5 & 1 & 1 & 9 & One parr missing \\
6 & 1 & 1 & 4 & One parr missing \\
7 & 1 & 2 & 10 & Female arrived prior to spawning \\
8 & 1 & 0 & 13 & Female left prior to spawning \\
9 & 1 & 1 & 5 & Male dead prior to spawning \\
10 & 0 & 1 & 9 & One parr missing; male left after spawning \\
11 & 2 & 1 & 5 & Two parr missing; unclear when 2nd \\
& & & & male arrived \\
12 & 1 & 1 & $?$ & No spawning-upstream section \\
13 & 1 & 1 & 20 & One parr dead; offspring triploid \\
\hline
\end{tabular}

Table 1 Number of anadromous males, anadromous females and mature male parr of Atlantic salmon in each section of an outdoor raceway after spawning in all sections had been completed variance, respectively, produced by an individual in its lifetime. We used the estimated value of individual fertilization success as a proxy for lifetime success both from each nest individually as well as for the entire treatment, the latter by weighting each nest equally.

\section{Results}

The number of anadromous fish and parr found in each section after spawning had been completed is given in Table 1. In cases where the number of anadromous males and females in each section differed from one, the anadromous fish had moved by leaping over the vexar barrier (with the exception of the female that punctured the barrier between sections 7 and 8). Genetic evidence later indicated that one of the anadromous males collected in section 11 had spawned in section 10. Four parr from section 8 were found to have spawned in section 7, thus the number of parr in the latter treatment present at the time of spawning might have ranged from 10 (number of parr identified as having spawned) to 23 (number of parr in both sections; Table 1). None of the females in the three uppermost sections (i.e. sections 4,8 and 12) spawned, possibly as a result of the disturbance generated by the water inflow originating at the top of these sections. In addition, the uppermost sections also contained more parr at the conclusion of the experiment than there had been at the start. We attributed this to the movement of parr via the inflow from the water source of the hatchery raceways. These additional parr could only potentially have been involved in spawning in section 7 due to the hole in the partition between sections 7 and 8 . In the end, we had results for fewer treatments than originally designed (four treatments: 5 , 10, 10, and 20 parr). However, we also had four additional treatments having parr: female: anadromous male ratios of 5:1:0, 7:2:1, 10-23:2:1 and 7:1:1-2 which provided interesting findings.

Allelic diversity in the wild Margaree River salmon was high for the four microsatellite loci examined (18, 16, 27, and nine alleles at Ssa202, Ssa197, Ssa171, and $S s a 85$, respectively). Gene diversity $\left(H_{\mathrm{e}}\right)$ was also high $(0.91,0.90,0.92$, and 0.76 at Ssa202, Ssa197, Ssa171, and Ssa85, respectively).

As expected, most offspring possessed one or two alleles at each locus. However, the offspring from the single-pair treatment with 20 parr possessed two or three alleles at Ssa202, Ssa197, and Ssa171, and one or two alleles at $S s a 85$. In this treatment, almost all (166/167) offspring possessed both maternal alleles (the female was a homozygote at Ssa85) and often one additional allele at each locus. The lone exception was an embryo lacking one of the maternal alleles at Ssa197. However, this individual was triploid at both $S s a 202$ and $S s a 171$, thus this missing allele at $\$ s a 197$ must have represented either a one-repeat mutation or only partial genomic triploidization. This finding was unexpected and the mechanism remains unclear. Previous occurrences of spontaneous triploids in fish are believed to have occurred by the fertilization of unreduced eggs (e.g. Thorgaard \& Gall, 1979 and references therein), although their observed frequency was relatively low. It seems unlikely that the triploidy found in our study can be attributed to any form of handling stress. Artificial methods used to prevent the second meiotic division to create triploids are typically performed within $20 \mathrm{~min}$ of fertilization and often do not have complete success (reviewed by Ihssen et al., 1990). Hybrid Atlantic salmon $\times$ brown trout (Salmo trutta) females backcrossed with either an Atlantic salmon or brown trout male can also produce triploids (e.g. 
Johnson \& Wright, 1986). Although this possibility cannot presently be excluded, the maternal alleles at all three tetranucleotide loci were in the size classes expected for Atlantic salmon.

\section{Effect of parr size on individual reproductive success}

There was great variation in parr reproductive success among treatments (Fig. 2) and, in most cases, there were also significant differences in individual reproductive success among nests within treatments. We found no evidence of an influence of parr body size on individual reproductive success in the single anadromous pair treatments (Fig. 2a-d). In the treatment with five parr (Fig. 2a), total parr success was low (mean of $4.7 \%$ ) with only two parr identified as having fertilized eggs, although in one of the three nests, the largest individual was the only parr to spawn (the number of parr displayed in Fig. $2 \mathrm{a}-\mathrm{d}$ is lower than the sample size for those treatments as a result of mortalities). Total parr success was higher in the two 10-parr treatments with seven and five parr identified as having been involved in spawning (average fertilization success of 55 and $26 \%$, as represented by Fig. $2 \mathrm{~b}$, c, respectively). In the 20-parr treatment, total parr success was also high (mean of $30 \%$ ) and 11 parr were identified as having been involved in spawning (Fig. 2d).
There was also little evidence of an influence of parr size on individual reproductive success in either of the treatments involving two anadromous females and one anadromous male (Fig. 2e, f), although in one of the four nests in the 10-23 parr treatment, the two most successful parr were the largest parr. In the treatment involving seven parr, six were identified as having been involved in spawning and mean total parr success was 76\% (Fig. 2e). In the 10-23 parr treatment (Fig. 2f), 10 parr were identified as having been involved in spawning and mean total parr success was $53 \%$.

There was no apparent influence of parr size on individual reproductive success in the treatment that, at the time of salmon removal, had two anadromous males and one anadromous female (Fig. $2 \mathrm{~g}$; section 11). The specific lengths of the two putative contributors were unknown but, given the lengths of the parr present, both must have been from the $91-110 \mathrm{~mm}$ size class. In one nest, parr had fertilized all of the eggs, with six of the seven parr identified as having spawned, while in the other nest examined, the anadromous male from section 10 had complete success.

There was a very strong relationship between individual parr size and individual reproductive success in the single treatment for which the anadromous male had died (Fig. 2h). In this treatment, all five parr were identified as having been involved in spawning with the largest parr fertilizing all the eggs in one nest and the
Fig. 2 Individual parr fertilization success in Atlantic salmon vs. parr length for the treatments involving a single anadromous pair and (a) five parr; (b) and (c) 10 parr; (d) 20 parr, one anadromous male, two anadromous females; (e) seven parr; (f) 10-23 parr, two anadromous males, one anadromous female; (g) seven parr, and no anadromous male, one anadromous female; and (h) five parr. $n$ refers to the number of equally weighted nests upon which the mean was calculated (the number of embryos in each nest upon which the frequencies were determined). The $r^{2}$ and associated $p$-values refer to the linear regressions between parr fertilization success and parr body size.

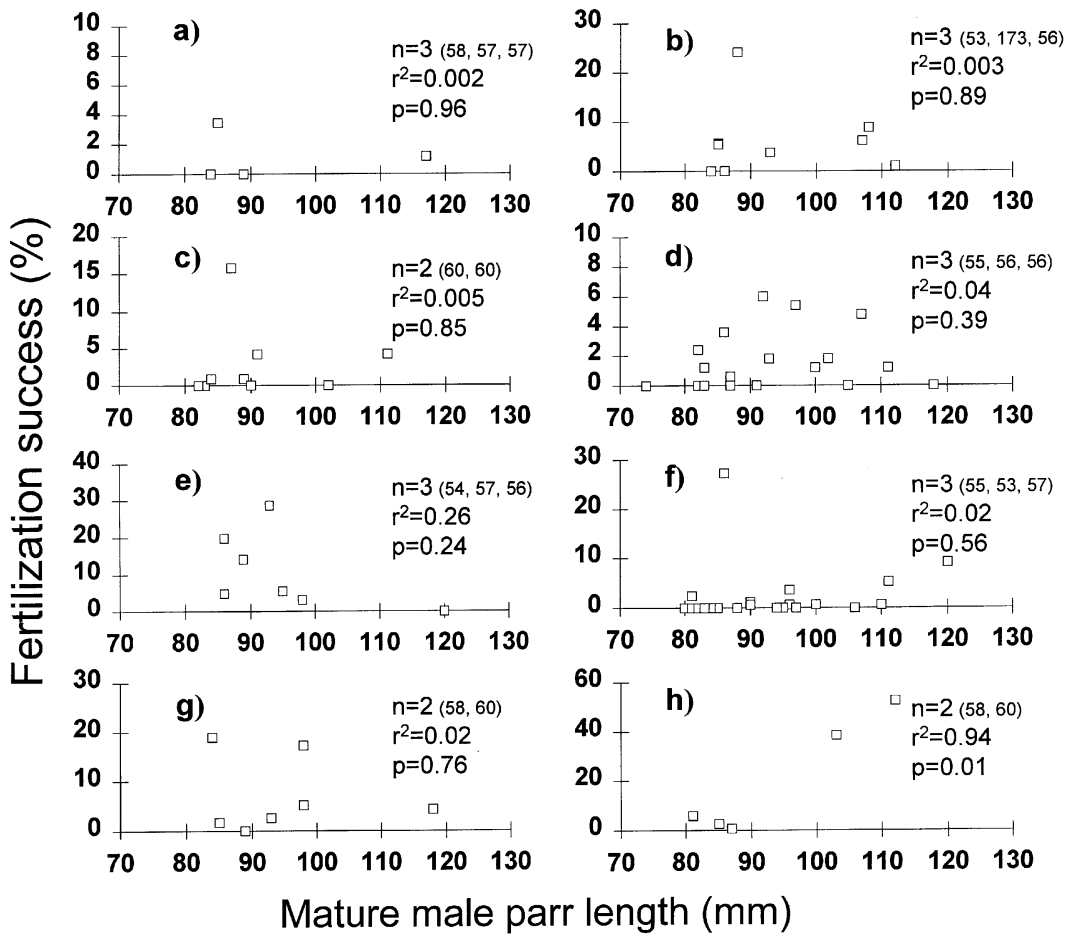

(C) The Genetics Society of Great Britain, Heredity, 86, 675-684. 
second largest parr obtaining the highest fertilization success in the other nest sampled.

\section{Parr mortality and the probability of not detecting individual paternity}

In all single-pair anadromous salmon treatments, there was evidence of parr mortality between the onset of the experiment (October 31 1996) and the removal of the salmon (December 9 1996). In three of these single-pair treatments (sections 5, 6, and 10), the number of parr collected was one less than at the start of the experiment, and in the fourth (section 13) a decomposing parr was found. In the other sections where spawning occurred, there was no parr mortality in the section where the anadromous male had died (section 9) or in the section with two anadromous females, one anadromous male, and seven parr. Two parr were missing from the section with two anadromous males (section 11).

In only one treatment was there evidence that the missing parr had successfully fertilized eggs. Given the high allelic diversity at each locus used in this study, the probability of such an individual being reproductively successful and not detected (i.e. falsely assigned to another individual in that section) is very low. The identification of unaccounted contributors in section 11 and the initial inability to account for all paternity in section 7 until males from section 8 were included as potential fathers provides strong supporting evidence that no additional, unsampled, deceased males had spawned successfully in any of the sections.

\section{Individual parr size and probability of spawning}

Although there was no relationship between individual reproductive success and parr size within or among treatments, larger parr appeared to be involved more frequently in spawning than smaller parr (Fig. 3). Combining results from all nests and dividing parr body sizes equally (i.e. $n=23$ in each size class) among three size classes, large parr $(96-120 \mathrm{~mm})$ were identified as having been involved in spawning much more frequently than small parr $(81-86 \mathrm{~mm})(P<0.01 ; G$-test, Sokal $\&$ Rohlf, 1981). Neither parr in the small nor large size classes differed in successful spawning events from those in the intermediate size class $(87-95 \mathrm{~mm})(P=0.37$ between small and intermediate size classes and $P=0.08$ between intermediate and large size classes).

The mean relative individual reproductive success was similar for all size classes $(10.5 \%, 10.6 \%$, and $9.3 \%$ for small, medium and large size classes, respectively), where relative individual parr success $=$ individual parr success/total parr success in a given treatment. The small size class was characterized by a higher variance in

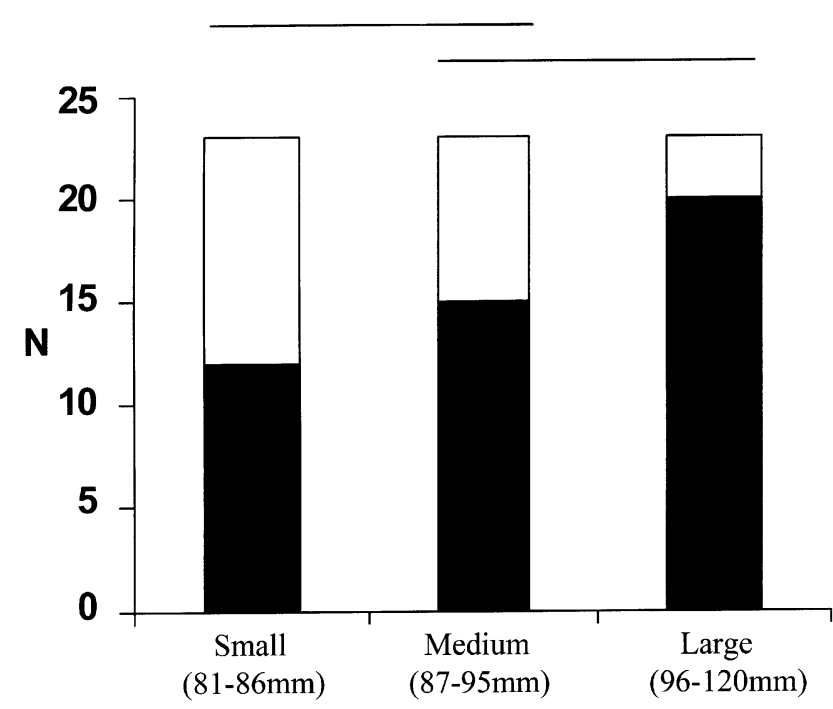

Fig. 3 Number of parr of different size classes in Atlantic salmon that did ( $\square$ ) and did not $(\square)$ successfully fertilize at least one egg. Bars connect size classes that did not differ significantly ( $G$-test).

relative individual reproductive success than the large size class $(0.044,0.028$, and 0.008 for small, medium and large size classes, respectively; because frequency data were used (to allow combining of data among treatments), variances were calculated using the arcsine of the frequencies (Sokal \& Rohlf, 1981)).

\section{Effect of intensity of anadromous male competition and effective number of males}

Parr fertilization success appeared to decline with increased intensity of anadromous male competition (no. anadromous males:no. anadromous females) (Fig. 4; the treatment with two anadromous males was excluded from the analysis because it was unclear when the second male had arrived during the experimental period). Parr success was higher in the two treatments with two anadromous females and one anadromous male than in the four treatments with one anadromous female and one anadromous male (63.8 vs. $28.7 \%$ ), although in one of the treatments with two anadromous females the number of parr may have been higher (10-23 parr) than in the other treatments.

To illustrate the potential influence mature male parr may have on effective population size, we calculated the effective number of males for each cross. There was no relationship between the effective number of males and the number of mature males (anadromous and parr) present in a treatment (data from Table 2; $r^{2}=0.003$, $P=0.90)$. However, mature male parr reproductive contributions increased the effective number of males 


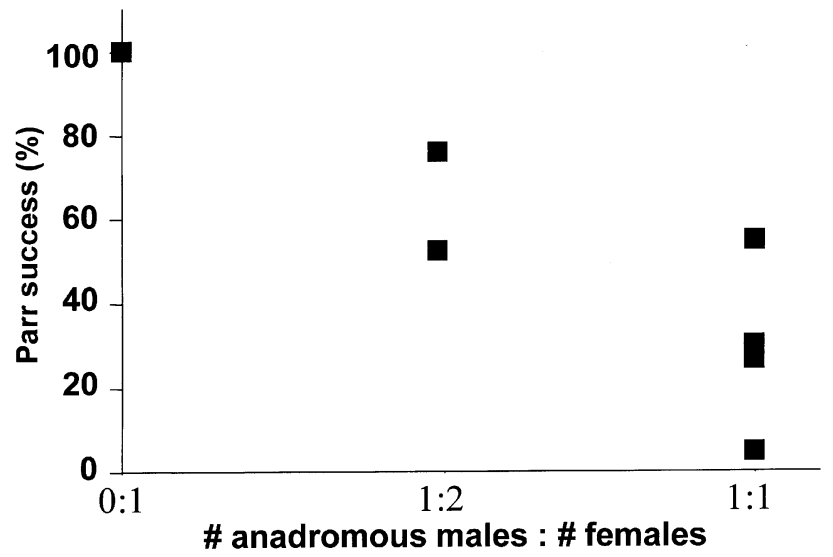

Fig. 4 Percent parr fertilization success vs. intensity of anadromous male competition in Atlantic salmon; the regression was significant with the inclusion of the treatment with no anadromous male $\left(r^{2}=0.75, P=0.012\right)$, but not with its exclusion $\left(r^{2}=0.51, P=0.108\right)$.

to more than one (the effective number of males there would have been had only one anadromous male and no parr been present) in all treatments (Table 2). This proportional increase in effective number of males relative to the number of anadromous males present appears to be related to the intensity of anadromous male competition. The increase in effective number of males as compared to the actual number of anadromous males present was marginal in the single anadromous pair treatment with five parr $\left(N_{\mathrm{e} \widehat{\sigma}^{t}}=1.10\right)$ but greater in the other single anadromous pair treatments $\left(N_{\mathrm{e} \widehat{\partial}}=1.75\right.$, 3.67, and 2.01) and generally greater still in the treatments involving two anadromous females and one anadromous male $\left(N_{\mathrm{e} \hat{\jmath}}=5.06\right.$ and 3.19; Table 2). In the treatment with five parr but no anadromous male, the effective number of males was greater than 2 (Table 2).
Of note is that, because different parr are often involved in each nest in a treatment, the overall effective number of males calculated by weighting each nest equally can be greater than the mean of the effective number of males from each nest (Table 2). This would result in our estimates of $N_{\mathrm{e}}{ }^{\hat{t}}$ being systematically biased downward. This bias is likely to be minimal as this effect will have an increasingly diminishing influence with each nest sampled; the overall increase in $N_{\mathrm{e} \widehat{C}}$ is only larger than that in each individual cross in only half the crosses (Table 2).

\section{Discussion}

\section{Effects of mature male parr and anadromous male competition on effective number of males}

To our knowledge, the present study is the first to estimate the effective number of males from individual fertilization success in fish. Although our results should not be taken as absolute, because we did not sample all nests and we used a proxy for lifetime reproductive success, they do illustrate how mature male parr can greatly increase the effective number of males when the latter is estimated from anadromous individuals alone. This result will be of particular importance for studying small Atlantic salmon populations given that anadromous females typically outnumber anadromous males during spawning. Genetic contribution from these nonmigratory parr will also serve to maintain genetic variation within populations and genetic differentiation among populations.

The total number of males present does not appear to influence the effective number of males. Of potentially greater importance to the effective number of males is the intensity of anadromous male competition. As the number of anadromous females per anadromous male increases, total parr reproductive success and,

Table 2 Number of anadromous males, anadromous females and mature male parr of Atlantic salmon in each section of an outdoor raceway during spawning, and the effective number of males $\left(N_{\mathrm{e} \delta}\right)$ calculated for each nest (i-iii) and overall (all). Mean fertilization success of parr, as a group, was calculated by weighting each nest equally

\begin{tabular}{|c|c|c|c|c|c|c|c|c|}
\hline Section & $\begin{array}{c}\text { No. of } \\
\text { anadromous } \\
\text { males }\end{array}$ & $\begin{array}{l}\text { No. of } \\
\text { anadromous } \\
\text { females }\end{array}$ & $\begin{array}{l}\text { No. of } \\
\text { mature } \\
\text { male parr }\end{array}$ & $N_{\mathrm{e} ð \widehat{i}}$ & $N_{\text {eởii }}$ & $N_{\text {eşiiii }}$ & $N_{\mathrm{e}{ }^{\widehat{\lambda}} \text { all }}$ & $\begin{array}{l}\text { Mean parr } \\
\text { success }(\%)\end{array}$ \\
\hline 6 & 1 & 1 & 5 & 1.07 & 1.07 & 1.15 & 1.1 & 4.7 \\
\hline 10 & 1 & 1 & 10 & 2.33 & 1.33 & - & 1.75 & 25.9 \\
\hline 5 & 1 & 1 & 10 & 1.88 & 2.95 & 2.89 & 3.67 & 55 \\
\hline 13 & 1 & 1 & 20 & 1.21 & 2.92 & 2.28 & 2.01 & 29.9 \\
\hline 3 & 1 & 2 & 7 & 3.96 & 1.34 & 2.17 & 5.06 & 75.8 \\
\hline 7 & 1 & 2 & $10-23$ & 2.01 & 2.15 & 2.95 & 3.19 & 52.5 \\
\hline 9 & 0 & 1 & 5 & 1 & 1.67 & - & 2.38 & 100 \\
\hline 11 & $1-2$ & 1 & 7 & 3.67 & 1 & - & 3.16 & 50 \\
\hline
\end{tabular}

(C) The Genetics Society of Great Britain, Heredity, 86, 675-684. 
consequently, the effective number of males both increase. The increase in total parr reproductive success could be the result of the anadromous male being unable to chase away parr from multiple females simultaneously. Alternatively, the anadromous male may become less able to fertilize as many eggs at each reproductive bout as sperm is depleted through repeated spawning (Mjølnerød et al., 1998). Irrespective of the cause, this finding suggests that the influence of mature male parr on effective population size will be greatest when population sizes are at their lowest and when the potential for loss of genetic variation is highest.

Some caution should be exercised when applying the results from this and other single anadromous pair treatment experiments to natural populations. Single anadromous pair treatment experiments, albeit with variation within and among studies, typically find total parr fertilization success to be approximately $30 \%$ (Hutchings \& Myers, 1988 - 20\%; Morán et al., 1996 - 51\%; Thomaz et al., 1997 - 30\%; present study $31 \%$ ). However, the degree to which such studies are representative of natural situations is difficult to assess. During spawning, anadromous females typically spawn over a few days whereas anadromous males can spawn for several weeks (Fleming, 1996). The result is that although anadromous salmon sex ratios are typically female-biased, the operational sex ratio on the spawning grounds may often be heavily male-biased (Fleming, 1996). The results from our study and a previous experiment (Jordan \& Youngson, $1992-11 \%$ mean total parr success) suggest that increased anadromous male competition will lead to a reduction in total parr reproductive success. Thus, perhaps in contrast to our single anadromous pair treatment experiments for which parr success always resulted in an increase - and often a very large increase - in the effective number of males relative to the number of anadromous males present, the effective number of males in multiple anadromous pair matings may be significantly less.

Alternatively, parr success may well be greater in the wild than in experimental conditions, even with increased anadromous male competition. When spawning in faster currents, the parr's advantage of closer proximity to the female's vent may be amplified due to the increased diluting effect the current will have on the sperm (Jones, 1959). Similarly, heterogeneous substrate should provide more hiding locations for parr than exist in many controlled experiments, potentially increasing the access by parr to females. Martinez et al. (2000) found that mature male parr can often obtain the majority of the fertilization success. Two studies which were not able to identify the life history type of each male also noted that secondary male contribution can be high (Thompson et al., 1998
- 29\%; Morán \& García-Vázquez, 1998 - 72\%). Thus, the factors influencing parr reproductive success in the wild, and its influence on effective population size, require further attention.

\section{Effect of parr size on individual reproductive success}

Our results suggest that, when competing with an anadromous male, individual parr body size does not influence individual parr reproductive success. The general lack of such an association was not anticipated. Male parr compete for proximity to the female prior to spawning and the largest parr is often the closest (Myers \& Hutchings, 1987). Thus, at low parr densities, we had expected there to be a fertilization advantage to being large. Two factors might explain the lack of such a relationship in our study. The first could be related to the importance of individual fertilization success in the first nest laid to the previous overall finding of a significant relationship between parr size and individual fertilization success at low parr density (Thomaz et al., $1997-n=6$ parr). Thomaz et al. (1997) found a significant association between parr size and individual reproductive success only in nests in which parr had spawned for the first time. It is unclear whether there is a continuous turnover of parr between spawning events when parr densities are low. If not, parr will rarely be spawning for the first time. Thus, our finding of no association between parr size and individual fertilization success may be typical under some natural situations.

The second factor which could account for the independence of individual parr reproductive success and parr size in our study may be related to the considerably greater range in parr size used in Thomaz et al.'s (1997) experiment (11-65 g vs. 5.9-20.6 g) and their greater representation of the extremes in size classes. Our range in parr size and the relative proportions of the size classes reflect those observed in the Margaree River. This range is probably representative of most Canadian populations, for which parr growth rates are lower than those in southern Europe (contrast parr lengths in France (e.g. Baglinière \& Maisse, 1985) with those in Atlantic Canada (e.g. Myers et al., 1986)). Thus, the influence of parr size on individual fertilization success may be lower in Canadian populations due to their smaller range in body size.

The lack of an association between parr size and individual reproductive success at higher parr densities (10 and 20 parr) appears to be robust. At these densities, total parr contribution was high (mean $27-55 \%$ vs. $5 \%$ for the treatment with five parr) and similar findings were obtained in three separate treatments. The lack of a relationship between individual 
parr size and reproductive success might be expected at higher parr densities given that, relative to low levels of mate competition, the dominant parr must presumably chase away more subdominant (smaller) parr to maintain increased access to the female. The difficulty of maintaining this favourable position would be expected to increase with larger numbers of parr as the dominant parr expends continually greater effort attempting to maintain his position to a point at which body size has no influence on fertilization success (Hutchings \& Myers, 1994). Our findings provide some support for this hypothesis.

Although larger parr were involved in more spawning events than smaller parr (Fig. 3), both size classes had similar mean relative individual reproductive success. Smaller parr, when involved in spawning, frequently had higher relative reproductive success than the larger parr that spawned. Consequently, smaller parr had much higher variance (0.044) in relative individual reproductive success than the largest parr (0.008). Although there is no clear explanation for this finding, it could be related to a greater survival cost of reproduction experienced by smaller parr.

In summary, we found no effect of parr body size on individual parr fertilization success. Parr body size does, however, appear to determine whether an individual parr fertilizes any eggs or not. Using our estimates of individual male reproductive success, we illustrated quantitatively the influence mature male parr fertilization success has on the effective number of males. Because total parr success appears to be inversely related to the intensity of anadromous male competition, mature male parr are likely to be most influential on effective population size when the number of anadromous males in a population is low.

\section{Acknowledgements}

This study would not have been possible without the help of many people. Leonard Forsythe provided advice on various aspects of the raceway set up and monitored the raceways during the experiment. Leonard Forsyth, Larry Forsyth, Larry Marshall, Paul LeBlanc, Mike Mason, and Kevin Davidson (Department of Fisheries and Ocean) participated in the collection of the anadromous fish. Dr Patrick O'Reilly provided primer sequences prior to their publication and offered lab advice. Doug Cook was a source of insight in the lab. Dr Tillmann Benfey provided possible explanations for the triploids. Tara McParland helped sampled the postspawned fish, offered valuable assistance in the laboratory and with scoring, and read various versions of the manuscript. Comments by anonymous reviewers resulted in an improved manuscript. Financial support for this study came from an NSERC operating grant to J.A.H.

\section{References}

BAGLiNiÈRe, J. L. AND MAISSE, G. 1985. Precocious maturation and smoltification in wild Atlantic salmon in the Armorican Massif, France. Aquaculture, 45, 249-263.

BERGLUND, I., SCHMITZ, M. AND LUNDQVIST, H. 1992. Seawater adaptability in Baltic salmon (Salmo salar): a bimodal smoltification pattern in previously mature males. Can. J. Fish. Aquat. Sci., 49, 1097-1106.

DANZMANN, R. G. 1997. PROBMAX: a computer program for assigning unknown parentage in pedigree analysis from known genotypic pools of parents and progeny. J. Hered., 88, 333.

FLEMING, I. A. 1996. Reproductive strategies of Atlantic salmon: ecology and evolution. Rev. Fish Biol. Fish., 6, 379-416.

GROSS, M. R. 1985. Disruptive selection for alternate life histories in salmon. Nature, 313, 47-48.

HANSEN, L. P., JONSSON, B., MORGAN, R. I. G. AND THORPE, J. E. 1989. Influence of parr maturity on emigration of smolting Atlantic salmon Salmo salar. Can. J. Fish. Aquat. Sci., 46, 410-415.

HEATH, D. D., POllard, S. M. AND HERBINGER, C. M. In press. Genetic differentiation and isolation by distance in steelhead trout (Oncorhynchus mykiss) populations in British Columbia. Heredity.

HERBINGER, C. M. AND NEWKIRK, G. F. 1990. Sources of family variability for maturation incidence in cultivated Atlantic salmon. Aquaculture, 85, 153-162.

HUTCHINGS, J. A. AND MYERS, R. A. 1988. Mating success of alternative maturation phenotypes in male Atlantic salmon, Salmo salar. Oecologia, 75, 169-174.

HUTCHINGS, J. A. AND MYERS, R. A. 1994. The evolution of alternative mating strategies in variable environments. Evol. Ecol., 8, 256-268.

IHSSEN, P. E., MCKAY, L. R., MCMILLAN, I. AND PHILLIPS, R. B. 1990. Ploidy manipulations and gynogenesis in fishes: cytogenetic and fisheries applications. Trans. Am. Fish. Soc., 119, 698-717.

JOHNSON, K. R. AND WRIGHT, J. E. 1986. Female brown trout $\mathrm{x}$ Atlantic salmon hybrids produce gynogens and triploids when backcrossed to male Atlantic salmon. Aquaculture, 57, 345-358.

JONES, J. W. 1959. The Salmon. Collins, London.

JORDAN, W. C. AND YOUNGSON, A. F. 1992. The use of genetic marking to assess the reproductive success of mature male Atlantic salmon parr (Salmo salar, L.) under natural spawning conditions. J. Fish Biol., 41, 613-618.

L'ABÉE-LUND, J. H. 1989. Significance of mature male parr in a small population of Atlantic salmon (Salmo salar). Can. J. Fish. Aquat. Sci., 46, 928-931.

LANDE, R. AND BARRowClOUGH, G. F. 1987. Effective population size, genetic variation, and their use in population management. In: Soule, M. E. (ed.) Viable Populations for Conservation, pp. 87-123. University Press, Cambridge. 
MARTINeZ, J. L., MORÁN, P., PEREZ, J., DE GAUdeMAR, B. ET $A L$. 2000. Multiple paternity increases effective size of southern Atlantic salmon populations. Mol. Ecol., 9, 293-298.

MILleR, M. P. 1997. Tools for population genetic analyses (TFPGA) v. 1.3. Department of Biological Sciences - Box 5640, Northern Arizona University, Flagstaff, AZ 860115640 .

MJøLNERøD, I. B., FLEMING, I. A., REFSETH, U. H. AND HINDAR, K. 1998. Mate and sperm competition during multiplemale spawnings of Atlantic salmon. Can. J. Zool., 76, $70-75$.

MORÁN, P. AND GARCÍA-VÁZQUEZ, E. 1998. Multiple paternity in Atlantic salmon: a way to maintain genetic variability in relicted populations. J. Hered., 89, 551-553.

MORÁN, P., PENDÁS, A. M., BEALL, E. AND GARCÍA-VÁZQUEZ, E. 1996. Genetic assessment of the reproductive success of Atlantic salmon precocious parr by means of VNTR loci. Heredity, 77, 655-660.

MYERS, R. A. AND HUTCHINGS, J. A. 1987. Mating of anadromous Atlantic salmon, Salmo salar L., with mature male parr. J. Fish Biol., 31, 143-146.

MYERS, R. A., HUTCHINGS, J. A. AND GIBSON, R. J. 1986. Variation in male parr maturation within and among populations of Atlantic salmon, Salmo salar. Can. J. Fish. Aquat. Sci., 43, $1242-1248$

O'CONNELL, M. AND WRIGHT, J. M. 1997. Microsatellite DNA in fishes. Rev. Fish Biol. Fish., 7, 331-364.
O'REILly, P. T. 1997. Development of Molecular Genetic Markers in Atlantic Salmon (Salmo salar) and an Illustration of Their Application to Aquaculture and Fisheries. PhD Dissertation. Dalhousie University.

O'REILlY, P. AND WRIGHT, J. M. 1995. The evolving technology of DNA fingerprinting and its application to fisheries and aquaculture. J. Fish Biol., 47 (Suppl. A), 29-55.

O'REILLY, P. T., HAMILTON, L. C., MCCONNELL, S. K. AND WRIGHT, J. M. 1996. Rapid analysis of genetic variation in Atlantic salmon (Salmo salar) by PCR multiplexing of dinucleotide and tetranucleotide microsatellites. Can. J. Fish. Aquat. Sci., 53, 2292-2298.

PRÉvoST, E., CHADWICK, E. M. P. AND CLAYTOR, R. R. 1993. Within-stock variation of life-history traits in juvenile Atlantic salmon (Salmo salar). Ecol. Fresh. Fish, 2, 73-83. SOKAL, R. R. AND ROHLF, F. J. 1981. Biometry, 2nd edn. W. H. Freeman, San Francisco.

THOMAZ, D., BEALL, E. AND BURKe, T. 1997. Alternate reproductive tactics in Atlantic salmon: factors affecting mature parr success. Proc. R. Soc. B, 264, 219-226.

THOMPSON, C. E., POOLE, W. R., MATTHEWS, M. A. AND FERGUSON, A. 1998. Comparison, using microsatellite DNA profiling, of secondary male contribution in the fertilisation of wild and ranched Atlantic salmon (Salmo salar) ova. Can. J. Fish. Aquat. Sci., 55, 2011-2018.

THORGAARD, G. H. AND GALL, G. A. E. 1979. Adult triploids in a rainbow trout family. Genetics, 93, 961-973. 